\title{
Analisa Pengaruh Jarak Sistem Proteksi Water Hammer Pada Sistem Perpipaan (Studi Kasus Di Rumah Pompa Produksi Unit Instalasi Pengolahan Air Minum (IPAM) Karang Pilang 3 Distribusi Wonocolo PT PDAM Surya Sembada Surabaya)
}

\author{
Firdaus Zakaria Nugraha dan Nur Ikhwan \\ Departemen Teknik Mesin, Fakultas Teknologi Industri, Institut Teknologi Sepuluh Nopember (ITS) \\ e-mail:nur_ikhwan@me.its.ac.id
}

\begin{abstract}
Abstrak-Sistem perpipaan digunakan sebagai instalasi umum untuk mengalirkan fluida. Pengaturan debit fluida dapat dilakukan dengan beberapa cara. Salah satunya adalah dengan pengaturan` valve. Penutupan valve yang terlalu cepat akan menimbulkan kenaikan tekanan yang sangat tajam sehingga menyerupai suatu pukulan dan dinamakan pukulan air (water hammer). Beberapa cara untuk mengurangi dampak water hammer adalah dengan cara menambahkan alat proteksi water hammer seperti surge tank atau bladder suge tank. Pada penelitian ini, pemodelan sistem perpipaan dilakukan dengan menggunakan bantuan perangkat lunak. Sistem perpipaan yang disimulasikan merupakan sistem perpipaan di IPAM Karang Pilang 3 dengan alat proteksi surge tank dan bladder surge tank. Analisa yang dilakukan adalah untuk mempelajari fenomena water hammer pada saat kondisi transient yakni ketika tiga pompa operasi mengalami kegagalan beroperasi. Pemodelan ini dilakukan sebagai tindak lanjut untuk mempelajari fenomena water hammer yang terjadi pada instalasi perpipaan dan juga melihat peran penggunaan alat proteksi baik itu surge tank maupun bladder surge tank beserta variasi jarak sistem proteksi water hammer terhadap pompa yakni 50 meter, 35 meter, 20 meter terhadap forwarding pump. Sehingga dengan jarak alat proteksi yang berbeda dapat dilihat pengaruh jarak terhadap unjuk kerja alat proteksi water hammer. Hasil perbandingan hasil simulasi transient antara surge tank dan bladder surge tank dalam meredam efek water hammer memberikan hasil perbedaan yang cukup berarti, yakni pada pada pemodelan pompa 3 OFF hasil fluktusi tekanan maksimum pada pipa 23 dengan menggunakan surge tank dengan jarak 20 meter terhadap forwarding pump tekanan maksimum mencapai 29,102 bar sedangkan dengan menggunakan bladder surge tank dengan jarak 20 meter terhadap forwarding pump tekanan maksimum mencapai 25,255 bar.
\end{abstract}

Kata Kunci-bladder surge tank, pressure, surge tank, water hammer.

\section{PENDAHULUAN}

$\mathrm{F}$ LUIDA merupakan aspek yang penting dalam kehidupan sehari-hari. Fluida adalah zat yang dapat mengalir. Kata fluida mencakup zat cair dan gas, karena kedua zat ini dapat mengalir, sebaliknya batu dan benda-benda keras atau semua zat padat tidak digolongkan ke dalam fluida karena tidak bisa mengalir. Sebagai contoh zat cair antara lain seperti air, susu, minyak, dan sebagainya.

Water hammer adalah fenomena terjadinya fluktuasi tekanan yang diakibatkan oleh penutupan valve yang cepat ataupun matinya pompa secara tiba-tiba sehingga menimbulkan lonjakan tekanan pada pompa dan pipa. Efek negatif yang dihasilkan oleh fenomena tersebut diantaranya adalah merusak valve, menimbulkan getaran pada pipa, menggetarkan tumpuan pipa dan menyebabkan kavitasi pada impeller pipa. Perubahan lonjakan tekanan yang terlalu tinggi dapat menyebabkan pipa rusak atau pecah. Fenomena ini mempunyai dampak buruk apabila sistem perpipaan tidak memperhatikan akibat dari water hammer.

Beberapa cara untuk mengurangi dampak water hammer adalah dengan menambahkan alat proteksi di daerah discharge pompa tersebut. Pemilihan alat proteksi water hammer yang tepat akan mempengauhi ketahanan sistem terhadap dampak water hammer yang terjadi. Penggunaan surge tank dan bladder surge tank pada daerah keluaran pompa akan dapat mengurangi lonjakan tekanan akibat efek water hammer. Penempatan jarak alat proteksi water hammer akan mempengarui performa alat proteksi water hammer dalam meredam fluktuasi tekanan akibat efek water hammer. Semakin dekat jarak alat proteksi water hammer terhadap rumah pompa maka semakin baik pula performa alat proteksi water hammer dalam meredam fluktuasi tekanan akibat efek water hammer pada daerah sekitar rumah pompa. Perbedaan jarak alat proteksi water hammer ini menjadi landasan untuk melakukan variasi jarak alat proteksi water hammer terhadap pompa yang akan digunakan dalam penelitian ini. 


\section{URAIAN PENELITIAN}

\section{A. Dasar Teori}

Fenomena water hammer terjadi ketika aliran dihentikan secara mendadak dan dirubah menjadi tekanan. Hubungan antara kecepatan dan perubahan tekanan dijelaskan dalam persamaan Joukowsky. Kecepatan perambatan gelombang tekanan di dalam pipa diformulasikan dari modulus bulk fluida dan modulus bulk elastisitas [1]. Kecepatan perambatan gelombang tekanan dapat diformulasikan sebagai berikut

$$
\begin{aligned}
& . \Delta p_{\text {jouk }}=\rho a \Delta v \\
& a^{2}=\frac{K / \rho}{1+c_{1}[(K / E)(D / e)]}
\end{aligned}
$$

dimana:

$$
\begin{array}{ll}
a & =\text { kecepatan gelombang fluida dalam pipa }(\mathrm{m} / \mathrm{sec}) \\
\Delta p & =\text { perubahan tekanan }\left(\mathrm{N} / \mathrm{m}^{2}\right) \\
\Delta v & =\text { perubahan kecepatan }(\mathrm{m} / \mathrm{sec}) \\
K & =\text { modulus bulk fluida }\left(\mathrm{N} / \mathrm{m}^{2}\right) \\
\rho & =\text { densitas fluida }\left(\mathrm{kg} / \mathrm{m}^{3}\right) \\
D & =\text { diameter pipa }(\mathrm{m}) \\
E & =\text { modulus elastisitas }\left(\mathrm{N} / \mathrm{m}^{2}\right) \\
e & =\text { ketebalan pipa }(\mathrm{m}) \\
c_{1} & =\text { faktor koreksi yang tergantung pada instalasi pipa. }
\end{array}
$$

\section{B. Surge Tank}

Surge tank berguna mengurangi fluktuasi water hammer. Surge tank adalah sebuah tank/vessel berbentuk seperti pipa yang sangat panjang yang salah satu ujungnya terhubung dengan udara luar dan ujung lainnya terhubung dengan pipa pada sistem perpipaan. Kelebihan tekanan pada perpipaan dibuang ke surge vessel sehingga tekanan berlebih pada pipa dapat dikurangi. Surge tank juga dapat mengatasi tekanan positif maupun negatif

\section{Bladder Surge Tank}

Bladder surge tank adalah sebuah tank penyimpanan sementara dari fluida bertekanan yang sekaligus mereduksi besarnya energi dari fluida akibat kondisi transient fluida. Dalam bladder surge tank terdapat sebuah kantong (bladder) yang menampung gas bertekanan. Gas yang digunakan biasanya berupa udara atau nitrogen. Energi yang dimiliki fluida akan terkompresi oleh bahan peredam yang terdapat dalam bladder surge tank dan disimpan sementara dalamnya untuk kemudian dalirkan kembali menuju pipeline.

Proses dalam mengurangi shock pressure dalam pipa dengan menggunakan bladder surge tank terjadi dalam tiga kondisi. Kondisi awal bladder surge tank dalam keadaan pre-charge dengan $p_{0}$ dan $V_{0}$. Dimana katub fluida dalam keadaan tertutup. Kemudian ketika tekanan minimum bekerja, maka terdapat sejumlah volume udara fluida $V_{l}$ yang mengkompresi bladder, hal yang sama pun terjadi ketika volume $V_{2}$ pada tekanan maksismum bekerja. Perbedaan antara kedua volume ini, dikatakan sebagai volume yang akan ditampung $\Delta V$ oleh bladder surge tank selama peristiwa water hammer terjadi. Dimana hubungan keduanya dapat dituliskan sebagai berikut [2]:

$$
\Delta V=V_{2}-V_{1}
$$

Untuk mengetahui spesifikasi bladder surge tank yang perlu diperhitungkan adalah parameter karateristik dari bladder surge tank. Parameter karateristik tersebut adalah volume gas kompresi. Volume gas kompresi diperlukan pada suatu bladder surge tank untuk mengurangi efek water hammer pada suatu sistem perpipaan. Secara matematis volume gas kompresi dapat dirumuskan sebagai berikut [2]:

$$
\begin{gathered}
V_{0}=\frac{\Delta V}{\left(\frac{p_{0}}{p_{1}}\right)^{\frac{1}{n}}-\left(\frac{p_{0}}{p_{2}}\right)^{\frac{1}{n}}} \\
p_{0}=0,9 \times p_{1}
\end{gathered}
$$

dimana:

$$
\begin{aligned}
& V_{0}: \text { volume gas kompresi bladder surge tank (liter) } \\
& n: \text { konstanta polytropic ( } 1,4 \text { untuk nitrogen) } \\
& p_{0}: \text { tekanan precharge gas } \text { (bar) } \\
& p_{1}: \text { tekanan minimum yang berkerja (bar) } \\
& p_{2}: \text { tekanan maksimum yang berkeja (bar) }
\end{aligned}
$$

\section{Estimasi Maximmum Internal Pressure Pipe Design}

Dengan menggunakan perhitungan tebal pipa discharge sesuai standar yang dikeluarkan oleh AWWA (American Water Works Association) Manual M11 maka dapat diketahui maximum internal pressure pipe design yang diizinkan dalam suatu pipa. Perhitungan maximum internal pressure pipe design dimaksudkan untuk melihat berapa pressure maksimal yang diizinkan atau batas pressure yang mampu diterima pipa ketika terjadi lonjakan tekanan akibat efek water hammer. Dengan data tebal, diameter, serta allowable design stress for steel pipe diketahui maka maximum internal design pressure pipa didapatkan dengan menggunakan persamaan Barlow sebagai berikut.

$$
p=\frac{2 \times S \times t \times M}{D}
$$

dimana:

$t=$ desain tebal pipa untuk internal design pressure $(\mathrm{mm})$

$p=$ maximum internal design pressure pipe design (bar)

$D=$ diameter dalam pipa, tidak termasuk coating (mm)

$S=$ allowable design stress for steel (bar)

$M=$ design factor $(0.875)$

\section{METODOLOGI}

\section{A. Simulasi Pemodelan Sistem Perpipaan}

Pemodelan dilakukan dengan menggunakan software sistem perpipaan sebagai alat bantu untuk melihat dampak yang ditimbulkan akibat fenomena aliran transient yang terjadi pada sistem perpipaan. Program ini akan menghitung tekanan transient pada sistem perpipaan dengan menggunakan iterasi dan metode matriks. Sedangkan metode karakteristik digunakan untuk memecahkan massa transient dan persamaan momentum pada aliran di dalam pipa.

Sistem perpipaan untuk rumah pompa produksi unit Instalasi Pengolahan Air Minum (IPAM) Karang Pilang 3 distribusi Wonocolo dimodelkan untuk melihat pengaruh penggunaan proteksi water hammer ketika mengalami kegagalan operasi. Pemodelan ini menggunakan dua skema pemodelan dengan proteksi water hammer surge tank dan bladder surge tank dengan skenario operasi pompa dimana tiga pompa mengalami kegagalan operasi secara ekstrim, yakni pada kondisi 3 pompa mati. 


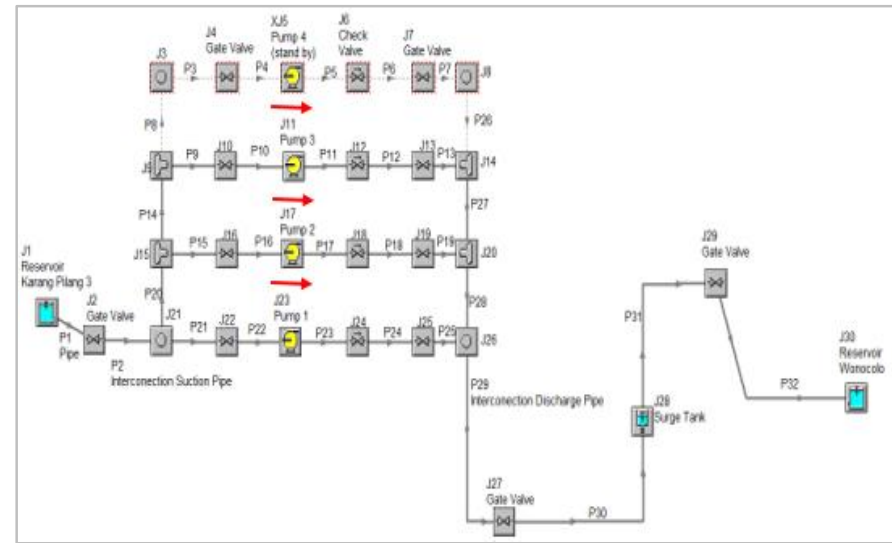

Gambar 1. Pemodelan sistem perpipaan pada software.

Jarak alat proteksi water hammer sangat berpengaruh terhadap performa alat proteksi water hammer dalam meredam fluktuasi tekanan akibat efek water hammer. Pada IPAM Karang Pilang 3 jarak alat proteksi surge tank yakni berjarak 50 meter dari forwarding pump. Dengan menggunakan maximum internal pressure pipe design di daerah discharge pump yakni 34,47 bar maka dapat dilihat apakah pada jarak 50 meter surge tank dapat meredam fluktuasi tekanan akibat efek water hammer dengan baik atau harus dilakukan variasi jarak untuk menentukan pada jarak berapa surge tank dapat meredam fluktuasi tekanan dengan baik. Variasi jarak ini juga akan digunakan pada alat proteksi bladder surge tank untuk kemudian membandingkan performa antara surge tank yang berada di IPAM Karang Pilang 3 dengan bladder surge tank hasil perhitungan beserta variasi jarak untuk kedua alat proteksi ini, sehingga dapat diketahui alat proteksi water hammer yang tepat beserta jarak yang idealnya

Tabel 1.

Variasi Jarak Surge Tank dan Bladder Surge Tank Terhadap Forwarding Pump di IPAM Karang Pilang 3 PT PDAM Surya Sembada Surabaya

\begin{tabular}{cccc}
\hline \hline & Variasi 1 & Variasi 2 & Variasi 3 \\
\hline $\begin{array}{c}\text { Jarak Surge } \\
\text { Tank }\end{array}$ & 50 meter & 35 meter & 20 meter \\
\hline \hline
\end{tabular}

\section{B. Spesifikasi Alat Proteksi Water Hammer}

Alat proteksi water hammer yang digunakan di IPAM Karang Pilang 3 PT PDAM Surya Sembada Surabaya adalah surge tank dengan spesifikasi sebagai berikut:

Tabel 2.

Spesifikasi Surge Tank

\begin{tabular}{cc}
\hline \hline Tank Height $\left(\mathrm{H}_{1}\right)$ & 6,7 meter \\
Tank Diameter $\left(\mathrm{D}_{1}\right)$ & 3,0 meter \\
Connector Pipe Diameter $\left(\mathrm{D}_{2}\right)$ & 0,6 meter \\
Elevation $\left(\mathrm{H}_{2}\right)$ & 1,0 meter \\
Tank Cross Section Area $\left(\frac{\pi}{4} \mathrm{D}^{2}\right)$ & 7,06 meter $^{2}$ \\
\hline \hline
\end{tabular}

Perhitungan volume Bladder surge tank dilakukan dengan melihat beberapa paramerter-parameter penting yakni tekanan maksimal dan minimal serta flow rate minimal dan maksimal yang terjadi saat kondisi transient yang paling ekstrim yaitu pada saat 3 pompa dalam keadaan mati. Setelah mengetahui kondisi water hammer pada kondisi ekstrim, maka selanjutnya adalah menentukan parameter-parameter pada kondisi tersebut untuk dijadikan data dalam perhitungan volume bladder surge tank yang dibutuhkan. Data yang diambil adalah data pada pipa discharge forwarding pump (pipa P29) karena pada pipa ini yang terkena efek water hammer paling tinggi..

Pada table 3 memperlihatkan parameter-parameter yang dibutuhkan untuk menghitung volume bladder surge tank. Pada table 3 terlihat empat parameter yang dibutuhkan untuk menghitung besarnya bladder surge tank, yang mana 2 diantaranya tekanan precharge didapat dari hasil perhitungan berdasarkan persamaan (5), sedangkan volume yang ditampung didapatkan dari profil perubahan volume pada saat masksimal dan minimal pada selang waktu tertentu selama water hammer atau transient condisition. Dari parameter yang telah ditentukan, maka parameter-parameter tersebut dapat langsung digunakan untuk menghitung besarnya volume bladder surge tank berdasarkan persamaan. Hasil perhitungan bladder surge tank dapat dilihat pada tabel 3.

Tabel 3.

Hasil Perhitungan Volume Bladder Surge Tank Pada Pipa 29

\begin{tabular}{cc}
\hline \hline \multicolumn{2}{c}{ Parameter-Parameter Bladder Surge Tank } \\
\hline Tekanan Maksimal (Bar) & 10,351 \\
Tekanan Minimal (Bar) & 0,028032 \\
Tekanan Precharge (Bar) & 0,02523 \\
Volume Yang Ditampung (Liter) & 2123,35 \\
& \\
Volume Gas Bladder Surge Tank & 2323,3 \\
(Liter) & \\
\hline \hline
\end{tabular}

\section{Titik Analisa Pemodelan}

Pada analisa pemodelan sistem perpipaan pada simulasi ini daerah yang dipilih adalah daerah yang terkena dampak utama ketika terjadai fenomena water hammer seperti halnya pada discharge pompa serta daerah dekat penempatan alat proteksi water hammer. Titik-titik analisa sama pada dua sistem operasi, yakni sebagai berikut.

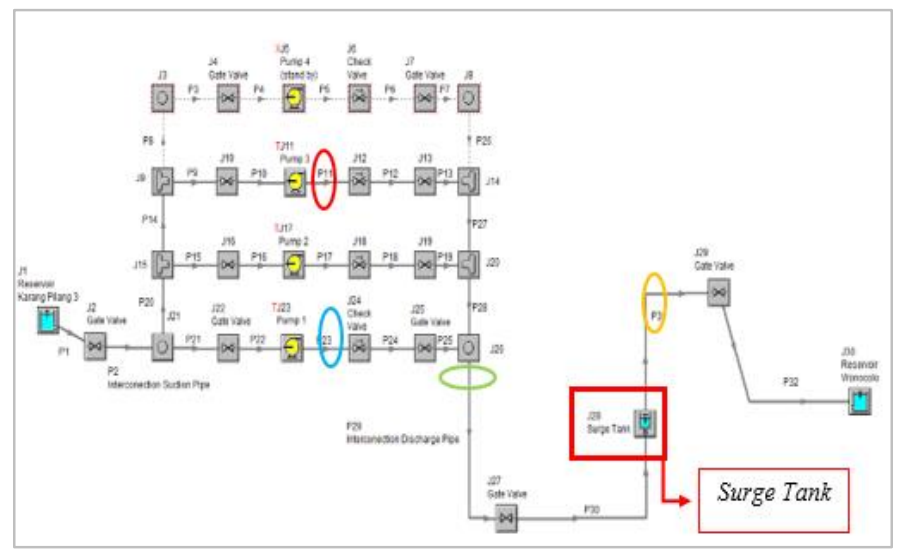

Gambar 2. Titik-titik Analisa Pada Simulasi Dengan Skenario 3 Pompa $O F F$ Dengan Sistem Proteksi Surge Tank. 


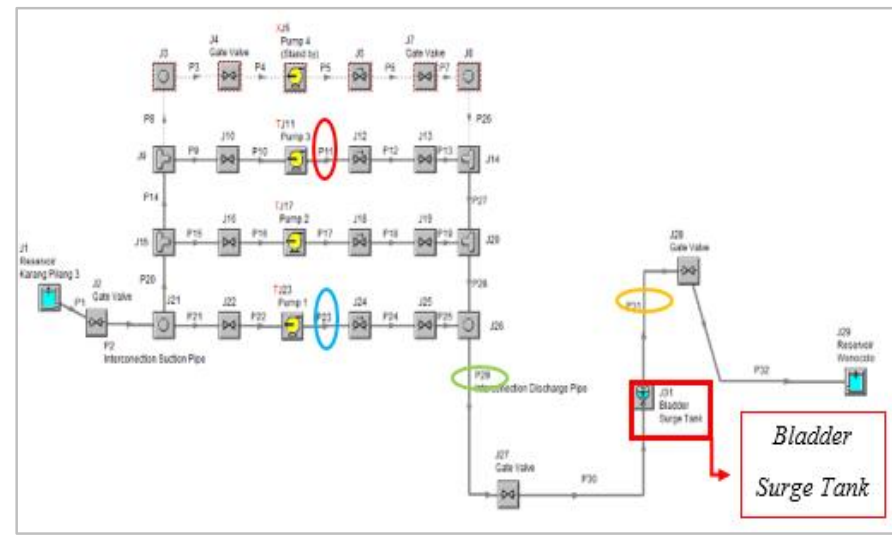

Gambar 3. Titik-titik Analisa Pada Simulasi Dengan Skenario 3 Pompa $O F F$ Dengan Sistem Proteksi Surge Tank .

Detail titik-titik analisa tersebut dijelaskan pada tabel di bawah ini

Tabel 4.

Detail Titik Analisa Pada Simulasi Dengan Skenario 3 Pompa OFF.

\begin{tabular}{llll}
\hline \hline No & Warna Pipa & Pomor Pipa & Posisi Pipa \\
\hline 1 & P11 & $\begin{array}{l}\text { Disharge } \\
\text { pompa 1 }\end{array}$ \\
& P29 & $\begin{array}{l}\text { Discharge } \\
\text { pompa 3 }\end{array}$ \\
3 & P31 & $\begin{array}{l}\text { Pipa Discharge } \\
\text { Utama }\end{array}$ \\
4 & & $\begin{array}{l}\text { Setelah sistem } \\
\text { proteksi }\end{array}$
\end{tabular}

\section{HASIL DAN PEMBAHASAN}

\section{A. Perhitungan Maximum Internal Pressure Pipe Design Pada Discharge Pump}

Dengan menggunakan maximum internal pressure pipe design ini dapat digunakan sebagai acuan untuk memilih alat proteksi water hammer yang tepat beserta jarak ideal alat proteksi water hammer terhadap pompa dalam meredam fluktuasi tekanan akibat efek water hammer.

Dengan data tebal pipa diketahui, maximum internal design pressure didapatkan dengan menggunakan persamaan Barlow sebagai berikut.

- Tebal pipa $(t) \quad=9,524 \mathrm{~mm}$

- Allowable design stress

$$
\text { for steel }(S) \quad=15.000 \mathrm{psi}=1034,21 \mathrm{bar}
$$

- Inside diameter,

$$
\text { exc. } \text { coatings }(D) \quad=489 \mathrm{~mm}
$$

- Design factor $(M)=0,875$

$$
\begin{aligned}
p & =\frac{2 \times S \times t \times M}{D} \\
& =\frac{2 \times 1034,21 \text { bar } \times 9,524 \mathrm{~mm} \times 0,875}{489 \mathrm{~mm}}=\mathbf{3 4 , 4 7 ~ b a r}
\end{aligned}
$$

\section{B. Hasil Simulasi Pada Skenario 3 Pompa OFF}

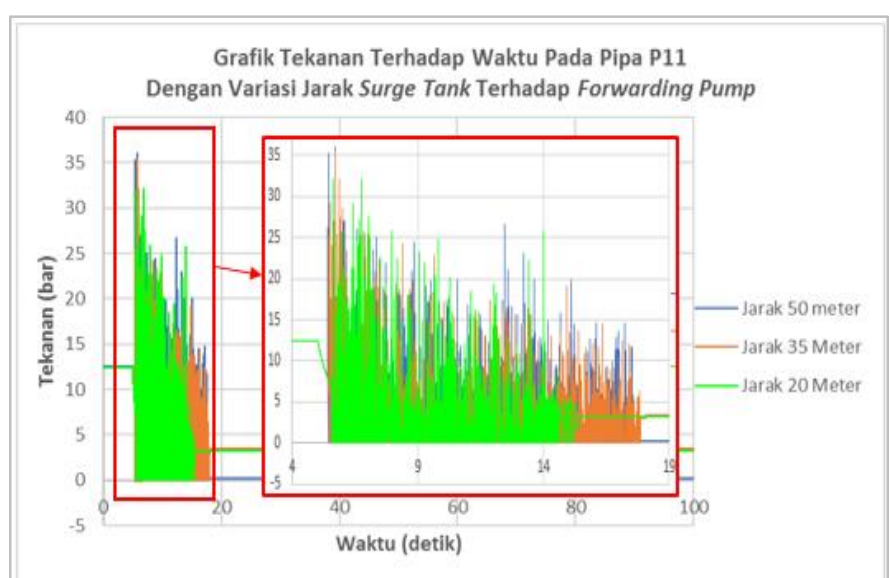

Gambar 4. Grafik Tekanan Terhadap Waktu Pada Pipa P11 Inlet (Discharge Pompa 3) Dengan Variasi Jarak surge tank Terhadap Forwarding Pump Pada Skenario 3 Pompa $O F F$.

Dengan menggunakan maximum internal pressure pipe design sebesar 34,47 bar sebagai acuan batas tekanan yang mampu diterima pipa maka dapat dilihat bahwa pada variasi jarak 50 dan 35 meter fluktuasi tekanan yang terjadi sangat tinggi melebihi tekanan maksimum yang diizinkan pada pipa discharge pump, sedangkan pada variasi jarak 20 meter tekanan maksimum yang terjadi berada dibawah batas aman tekanan yang diizinkan pada pipa discharge pump yaitu 32,164 bar.

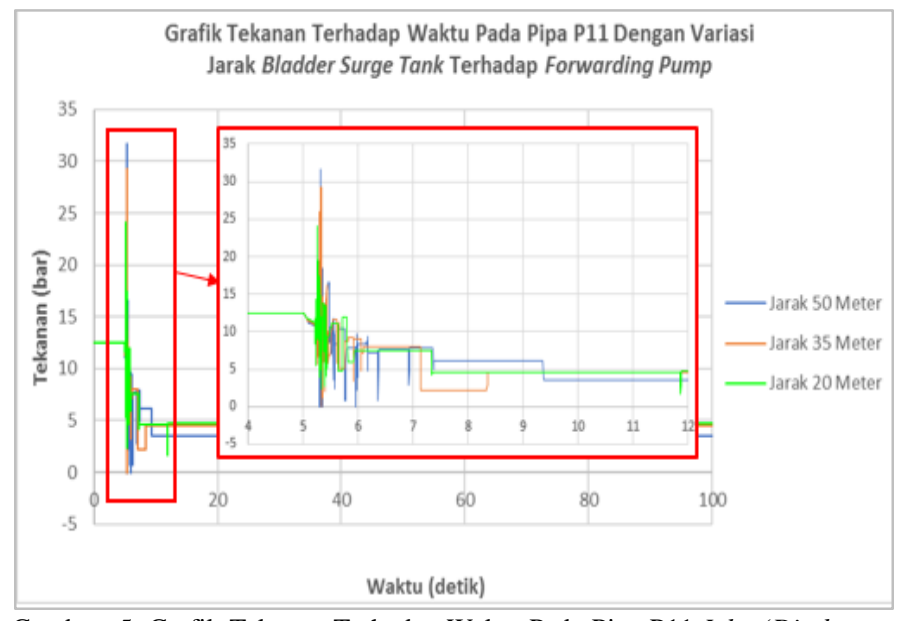

Gambar 5. Grafik Tekanan Terhadap Waktu Pada Pipa P11 Inlet (Discharge Pompa 3) Dengan Variasi Jarak Bladder Surge Tank Terhadap Forwarding Pump Pada Skenario 3 Pompa $O F F$.

Dari data hasil simulasi menunjukan pengaruh penggunaan sistem proteksi water hammer terhadap fluktuasi tekanan yang terjadi akibat efek water hammer. Dengan menggunakan maximum internal pressure pipe design sebesar 34,47 bar sebagai acuan batas tekanan yang mampu diterima pipa maka dapat dilihat bahwa pada ketiga variasi jarak 50, 35, dan 20 meter fluktuasi tekanan yang terjadi berada dibawah batas aman tekanan yang diizinkan pada pipa discharge pump, namun pada jarak 20 meter bladder surge tank mampu meredam fluktuasi tekanan yang lebih baik dibandingan pada jarak 50 dan 35 meter dengan tekanan maksimal mencapai 24,658 bar. 


\section{Perbandingan Grafik Untuk Pemodelan Surge Tank Vs Pemodelan Bladder Surge Tank}

Berdasarkan hasil grafik simulasi yang dilakukan pada pemodelan surge tank dan bladder surge tank beserta variasi jarak pada saat kondisi 3 pompa off dapat dilihat bahwa untuk kedua sistem proteksi surge tank dan bladder surge tank dengan jarak 20 meter dari forwarding pump mampu meredam fluktuasi tekanan yang lebih baik dibandingkan dengan jarak alat proteksi 50 dan 35 meter. Sehingga akan dilakukan perbandingan antara surge tank dengan bladder surge tank pada jarak 20 meter untuk mengetahui perbandingan kemampuan dalam meredam efek water hammer pada kedua alat proteksi surge tank dan blader surge tank.

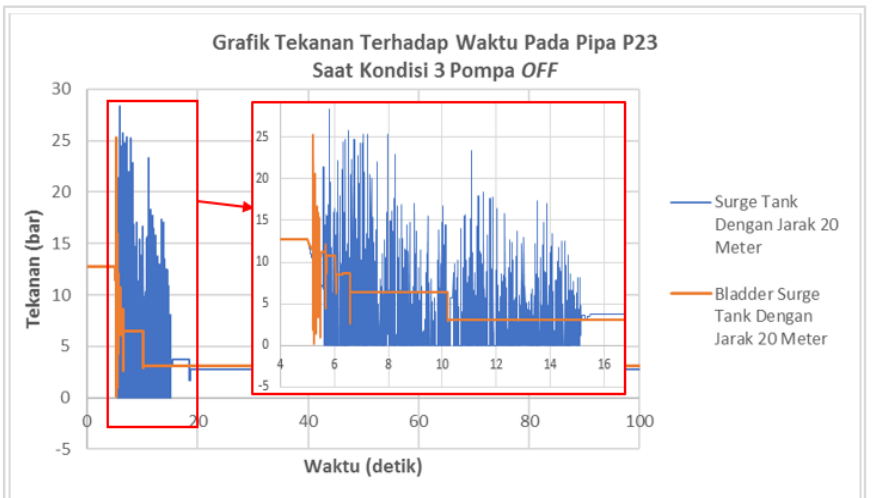

Gambar 8. Grafik Perbandingan Tekanan Terhadap Waktu Pada Pipa 23 Inlet Dengan Varisai Jarak Surge Tank 20 meter vs Pipa 23 Inlet Dengan Variasi Jarak Bladder Surge Tank 20 meter Pada Skenario 3 Pompa OFF.

Titik yang dibandingkan yakni pada pipa P23 inlet yang merupakan pipa discharge pompa 1 yang paling rentan terkena hantaman lonjakan tekanan akibat water hammer karena posisinya yang paling dekat dengan pipa keluaran utama. Dengan variasi jarak alat proteksi terhadap forwarding pump yang digunakan yakni 20 meter. Dari grafik perbandingan terlihat bahwa pada pemodelan dengan menggunakan blaldder surge tank mempunyai peran yang lebih baik dalam merendam fluktuasi tekanan akibat efek water hammer dibandingkan dengan menggunakan surge tank. Pemodelan dengan variasi jarak surge tank 20 meter mencapai tekanan maksimum 29,102 bar sedangkan pada pemodelan dengan bladder surge tank nilai tekanan maksimum yang terjadi mencapai 25,255 bar.

Peran bladder surge tank dalam meredam fluktuasi tekanan ini lebih baik dari pada surge tank dikarenakan di dalam bladder surge tank terdapat sebuah peredam (bladder) yang mampu untuk meredam fluktuasi tekanan water hammer dengan baik dibandingkan dengan surge tank yang tidak memiliki peredam (bladder).

\section{KESIMPULAN}

Berdasarkan simulasi dan analisa pemodelan yang dilakukan untuk layout sistem instalasi perpipaan di unit IPAM Karang Pilang 3, didapatkan beberapa kesimpulan sebagai berikut.

1. Hasil simulasi numerik untuk layout sistem instalasi di unit IPAM Karang Pilang 3 dengan variasi jarak alat proteksi water hammer saat pompa 3 OFF baik dengan menggunakan surge tank atau bladder surge tank fluktuasi tekanan paling tinggi terjadi pada pipa 11 yaitu discharge pompa 1, karena pada pipa ini terletak paling jauh dari sistem proteksi water hammer.

2. Berdasarkan hasil simulasi dan analisa yang dilakukan untuk layout system instalasi di unit IPAM Karang Pilang 3 dengan variasi jarak alat proteksi water hammer 50, 35 dan 20 meter terhadap forwarding pump, pada jarak 20 meter menghasilkan nilai peak yang paling rendah dan fluktuasi tekanan lebih cepat stabil dibandingkan jarak alat proteksi 50 dan 35 meter.

3. Berdasarkan hasil perbandingan hasil simulasi transient antara surge tank dan bladder surge tank dalam meredam efek water hammer memberikan hasil perbedaan yang cukup berarti, yakni pada pemodelan pompa 3 OFF hasil fluktusi tekanan maksimum pada pipa 23 dengan menggunakan surge tank dengan jarak 20 meter terhadap forwarding pump tekanan maksimum mencapai 29,102 bar sedangkan dengan menggunakan bladder surge tank dengan jarak 20 meter terhadap forwarding pump tekanan maksimum mencapai 25,255 bar.

\section{UCAPAN TERIMA KASIH}

Penulis Firdaus Zakaria Nugraha mengucapkan terima kasih pihak PT PDAM Surya Sembada Surabaya dan Unit IPAM Karang Pilang 3 atas kesempatan yang diberikan untuk mempelajari lebih lanjut tentang fenomena water hammer pada sistem perpipaan yang sangat berperan dalam penyusunan tugas akhir ini.

\section{DAFTAR PUSTAKA}

[1] L. Jonsson, "Mean Velocity Profiles in Transient Flows," in Proc 9th and last Round Table on Water Column Separation, 1900.

[2] M. Bhavan, Criteria For Hydraulic Design Of Surge Tank. New Delhi: Bureu of Indian Standards, 1998. 